\title{
Enlarging pediatric ectopic Rathke's cleft cyst in the prepontine cistern: case report
}

\author{
Takamasa Kamei, MD, ${ }^{1}$ Masahiro Nonaka, MD, PhD, ${ }^{1}$ Yoshiko Uemura, MD, PhD, ${ }^{2}$ \\ Yasuo Yamanouchi, MD, PhD, ${ }^{1}$ Yumiko Komori, MD, ${ }^{1}$ Ryoichi Iwata, MD, ${ }^{1}$ Junichi Takeda, MD, ${ }^{1}$ \\ Tetsuo Hashiba, MD, PhD, ${ }^{1}$ Kunikazu Yoshimura, MD, PhD, ${ }^{1}$ and Akio Asai, MD, PhD1
}

Departments of ${ }^{1}$ Neurosurgery and ${ }^{2}$ Pathology and Laboratory Medicine, Kansai Medical University, Hirakata, Osaka, Japan

\begin{abstract}
Rathke's cleft cyst is a cystic disease that occurs in the sella turcica or, occasionally, in the suprasellar area. An ectopic Rathke's cleft cyst is extremely rare, and its nature is less well understood. The authors report the case of a 14-year-old girl who presented with a growing cystic lesion in the prepontine cistern, immediately behind the dorsum sellae. Preoperative imaging and intraoperative investigation showed part of the cyst wall continuing into the dorsum sellae, to the pituitary gland. The cisternal portion of the cyst wall was totally resected via a right subtemporal approach. Histopathological examination of the cyst wall showed a monolayer of ciliated cells, identical to those of Rathke's cleft cyst. To the best of the authors' knowledge, this represents the first pediatric case of Rathke's cleft cyst occurring in the prepontine cistern.
\end{abstract}

https://thejns.org/doi/abs/10.3171/2017.6.PEDS1727

KEY WORDS Rathke's cleft cyst; ectopic; pediatric; oncology

$\mathrm{R}$ ATHKE's cleft cyst mostly occurs in the sella turcica and suprasellar areas. Occurrence in other areas is rare, representing ectopic Rathke's cleft cyst. Normally, Rathke's pouch closes in early embryogenesis, and Rathke's cleft cyst arises when a remnant of the pouch grows between the pars distalis and pars nervosa of the pituitary. ${ }^{13}$ We encountered a case of enlarging pediatric ectopic Rathke's cleft cyst in the prepontine cistern.

\section{Case Report}

The patient was a 14-year-old girl with no history of disease. MRI, performed because she was experiencing headaches and dizziness, revealed a circular cystic mass measuring $14 \times 10 \times 9 \mathrm{~mm}$ in the prepontine cistern behind the dorsum sellae and a spinous structure extending to the pituitary gland. The cyst was located in the upper half of the prepontine cistern. It appeared hypointense on T1-weighted images and isointense on T2-weighted images, with no areas of high intensity on diffusion-weighted images and no contrast enhancement (Fig. 1). We carefully followed this patient, and another MRI study 10 months later revealed enlargement of the cystic lesion to $18 \times 13 \times$ $10 \mathrm{~mm}$, as well deformation of the original shape. FLAIR imaging showed trabecular structures reaching the cyst from the pars intermedia of the pituitary (Fig. 2). DICOM (Digital Imaging and Communications in Medicine) data of the MRI studies were transferred to iPlan 2.5 software (Brainlab). Several trajectories for surgical approaches were then determined, including transsylvian, suboccipital, transclival, and subtemporal routes. We decided to 

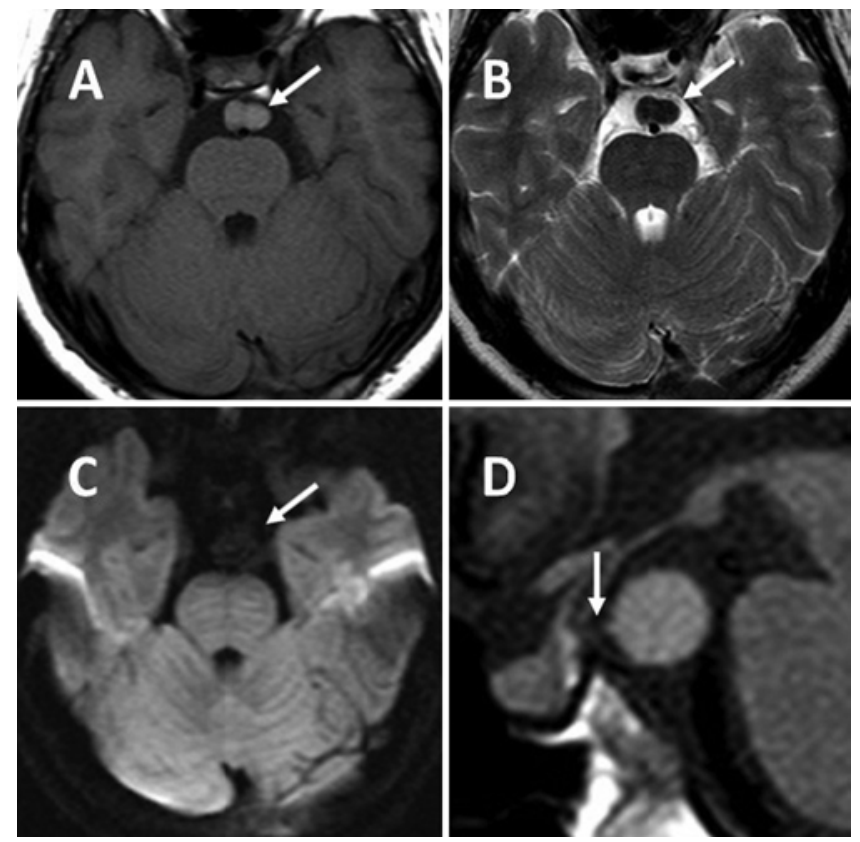

FIG. 1. Imaging at first visit. A: Axial T1-weighted image showing a homogeneous hyperintense round mass in the prepontine cistern (arrow). B: Axial T2-weighted image demonstrating a low-intensity mass (arrow). C: Diffusion-weighted image showing no signal-hyperintense content in the cyst (arrow). D: Sagittal T1-weighted image revealing a "spur" pointing to the dorsum sellae (arrow).

resect the cyst via a right subtemporal approach. After gently retracting the temporal lobe, the arachnoid of the prepontine cistern was incised. The yellowish-white cyst was detected in the prepontine cistern, which was filled with milky-white viscous fluid. After removing the cyst contents by suction, we totally resected the cisternal portion of the cyst wall (Fig. 3).

Histopathological examination showed the cyst wall to be lined by ciliated epithelium. The histopathological diagnosis was Rathke's cleft cyst (Fig. 4). The patient's postoperative course was uneventful. Her preoperative symptoms resolved after surgery, and as of the time of writing,
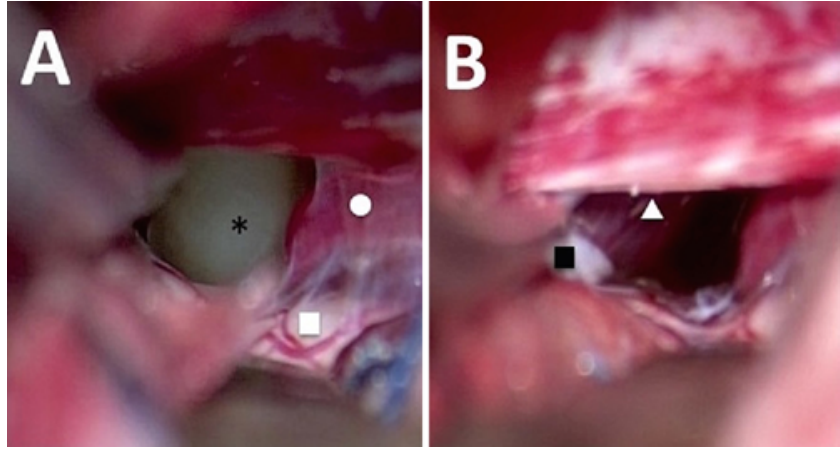

FIG. 3. Intraoperative photographs. A: A yellowish-white cyst is observed in the prepontine cistern. B: Collapsed cyst wall showing attachment to the dorsum sellae. Asterisk shows the cyst; white circle, the posterior cerebral artery; white square, the temporal lobe; black square, the collapsed cyst wall; and white triangle, the dorsum sellae. Figure is available in color online only.

she has remained symptom free for a year. Postoperative MRI performed 3 months after surgery suggested total resection of the lesion in the cisternal portion (Fig. 5).

\section{Discussion}

Among the various types of nonneoplastic intracranial cystic disease, Rathke's cleft cyst is one of the most frequently encountered clinically. Most are located in the sella turcica and suprasellar regions. The authors of most previous reports of ectopic Rathke's cleft cyst have described extracranial lesions, located in the nasopharynx or sphenoid sinus. ${ }^{3}$ To date, only 3 reports appear to have described intracranial ectopic Rathke's cleft cyst. Two lesions were located at the cerebellopontine angle, ${ }^{6,16}$ including one pediatric case, ${ }^{16}$ and in one adult case the lesion was located in the prepontine cistern ${ }^{12}$ (Table 1).

The cyst in our case was located in the upper half of the prepontine cistern. MRI showed a trabecula-like structure reaching the cyst from the interbulbar cleft on FLAIR imaging. We considered this finding as suggestive that the cyst originated in Rathke's cleft and grew into the prepontine cistern. Extension of the suprasellar Rathke's cleft
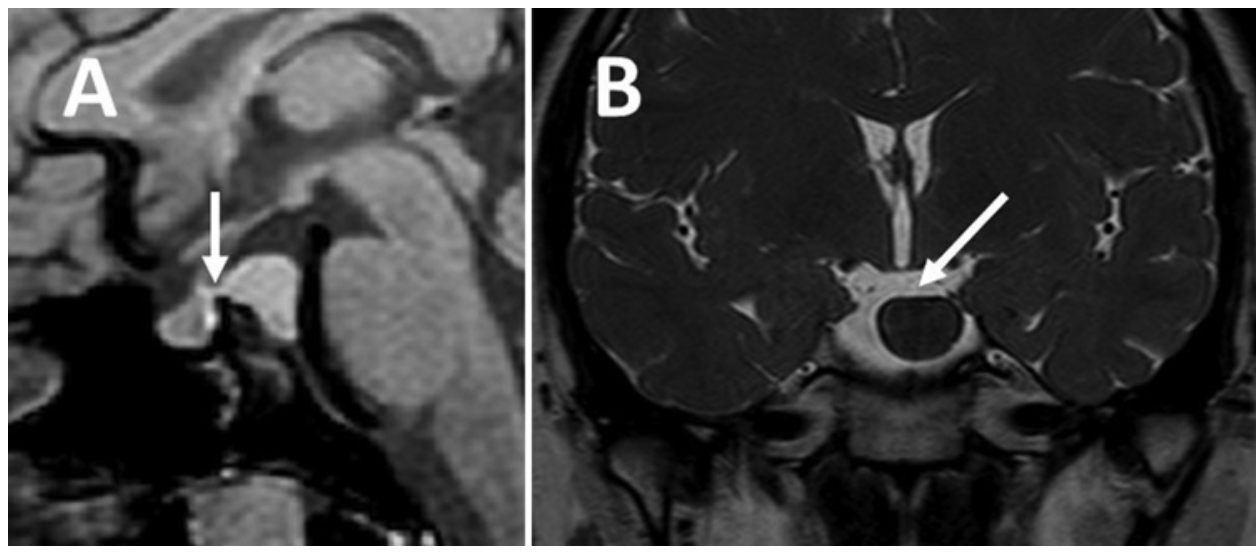

FIG. 2. A: Preoperative sagittal FLAIR image showing enlargement and distortion of the cyst shape compared with the image obtained on the first visit. Note the part of the cyst hanging over the dorsum sellae (arrow). B: Preoperative coronal heavily weighted T2 image revealing the location of the cyst (arrow) in the prepontine cistern. 


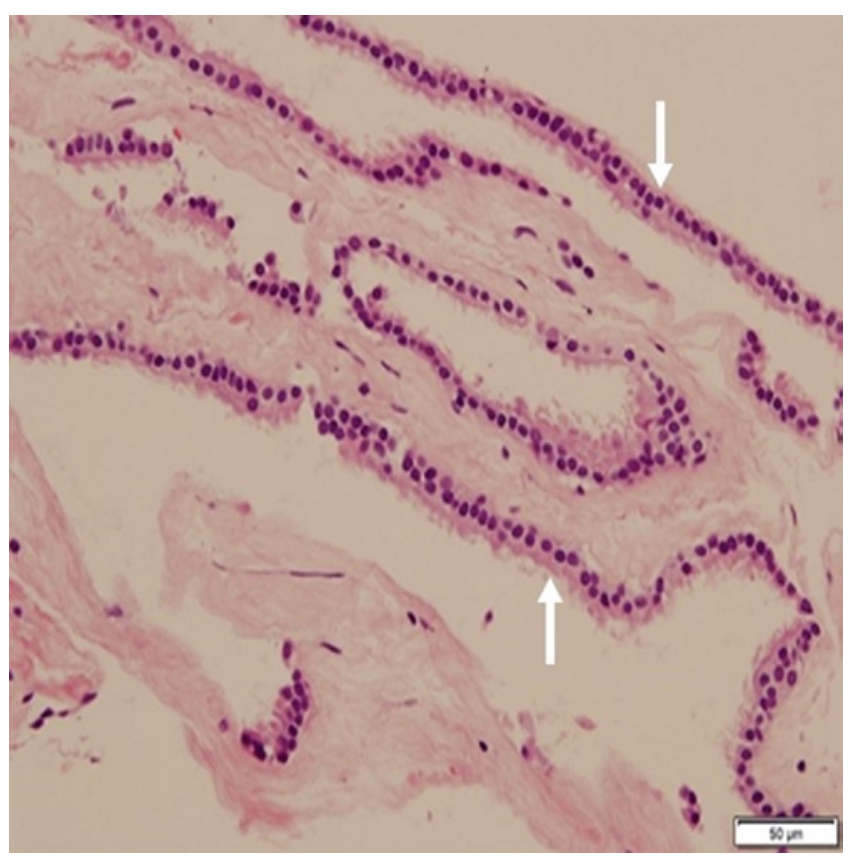

FIG. 4. Photomicrograph showing the cyst wall lined by ciliated epithelium (arrows). $\mathrm{H} \& \mathrm{E}$, original magnification $\times 100$. Figure is available in color online only.

cyst to the prepontine cistern has been reported previously. ${ }^{5}$ However, the cystic mass in our case was not found in either the supra- or intrasellar regions.

The natural course of ectopic Rathke's cleft cyst has not been described. Furthermore, there are no cases in which enlargement of the cyst was captured on images. Our report offers the first documentation of enlargement of the prepontine cyst in a pediatric case approximately 1 year after initial MRI.

Other cystic diseases, such as colloid cyst, ${ }^{11}$ epithelial cyst, ${ }^{8,10}$ and neurenteric cyst, show similar histopathological characteristics. ${ }^{9}$ Neurenteric cysts are known to occur on the ventral side of the spinal cord, along the course of the notochord. Some reports have described very rare neurenteric cysts occurring at the cerebellopontine angle, craniovertebral junction, and lower prepontine regions. ${ }^{1,2,7}$ The cyst in our case was located only in the upper prepon-
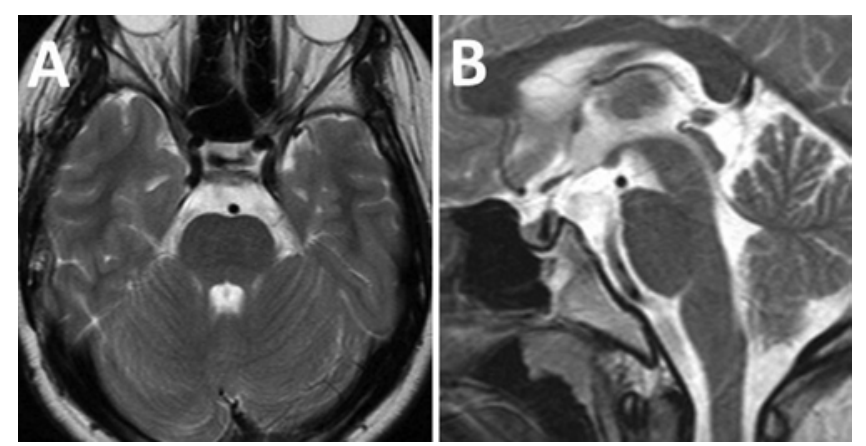

FIG. 5. Axial (A) and sagittal (B) T2-weighted images obtained 3 months after surgery, showing no residual lesion in the prepontine cistern.

tine region, where neurenteric cysts have not previously been reported.

Various surgical approaches have been applied to access prepontine lesions, including lateral suboccipital and transsylvian routes ${ }^{8,10-12}$ Since the cyst in our case was located in the upper half of the prepontine cistern, we carefully selected the surgical approaches. We applied iPlan surgical planning software and used the "trajectory view" to determine the surgical approach (Fig. 6). ${ }^{15}$ If the transsylvian approach is to be selected, the posterior clinoid process and dorsum sellae would need to be drilled off to allow visualization of the cyst. Drilling of the posterior clinoid process needs to be performed with extreme care to avoid injuring the posterior communicating artery and oculomotor nerve. Furthermore, opening of the venous plexus in the posterior clinoid process risks venous hemorrhage, ${ }^{4}$ which is not easy to control once it occurs. If a lateral suboccipital approach is used, brainstem retraction is required to reach the lesion, since the cyst is located behind the brainstem. Retraction of the brainstem carries a risk of damaging this structure, with disastrous consequences. Another approach is to reach the skull base where the cyst is located via the nasal cavity, using an endoscope. The transclival endoscopic endonasal approach may be useful, but it requires a high degree of technical skill to drill the thick clival bone appropriately, avoid damage to the normal pituitary gland, and prevent cerebrospinal fluid leakage. ${ }^{14}$

We therefore considered the subtemporal approach as useful for resection of the cyst located in the upper half

TABLE 1. Summary of intracranial ectopic Rathke's cleft cysts described in the literature

\begin{tabular}{|c|c|c|c|c|c|c|}
\hline $\begin{array}{c}\text { Authors \& } \\
\text { Year }\end{array}$ & $\begin{array}{l}\text { Age (yrs), } \\
\text { Sex }\end{array}$ & Symptoms & Lesion Size (mm) & MRI Features & Lesion Location & $\begin{array}{l}\text { Histopathological } \\
\text { Finding }\end{array}$ \\
\hline $\begin{array}{l}\text { Fan et al., } \\
2014\end{array}$ & $25, \mathrm{M}$ & $\begin{array}{l}\text { HA, vertigo, tinnitus, } \\
\text { hearing impairment }\end{array}$ & $38 \times 30 \times 25$ & $\begin{array}{l}\text { T1: low intensity; T2: } \\
\text { high intensity; CE }\end{array}$ & $\begin{array}{l}\text { Cerebellopontine } \\
\text { angle }\end{array}$ & $\begin{array}{l}\text { Single-layer columnar } \\
\text { epithelium }\end{array}$ \\
\hline Kim, 2012 & $41, \mathrm{~F}$ & $\mathrm{HA}$ & 25 & $\begin{array}{l}\text { T1: isointense; T2: } \\
\text { hypointense; CE }\end{array}$ & $\begin{array}{l}\text { Upper half of the } \\
\text { prepontine cistern }\end{array}$ & $\begin{array}{l}\text { Ciliated columnar } \\
\text { epithelium }\end{array}$ \\
\hline $\begin{array}{l}\text { Zhou et al., } \\
2010\end{array}$ & $12, F$ & $\begin{array}{l}\mathrm{HA} \text {, vertigo, nausea, } \\
\text { vomiting }\end{array}$ & Not available & $\begin{array}{l}\text { T1: hyperintense; T2: } \\
\text { hypointense; CE }\end{array}$ & $\begin{array}{l}\text { Cerebellopontine } \\
\text { angle }\end{array}$ & $\begin{array}{l}\text { Simple ciliated colum- } \\
\text { nar epithelium }\end{array}$ \\
\hline $\begin{array}{c}\text { Present } \\
\text { case }\end{array}$ & $14, F$ & $\mathrm{HA}$, dizziness & $14 \times 10 \times 9(\rightarrow 18 \times 13 \times 10)^{*}$ & $\begin{array}{l}\text { T1: low intensity; T2: } \\
\text { high intensity; CE }\end{array}$ & $\begin{array}{l}\text { Upper half of the } \\
\text { prepontine cistern }\end{array}$ & $\begin{array}{l}\text { Lined by ciliated } \\
\text { epithelium }\end{array}$ \\
\hline
\end{tabular}

$\mathrm{CE}=$ indication that there was no contrast enhancement of the cyst wall; $\mathrm{HA}=$ headache.

* Parenthetical value indicates the size the lesion grew to 10 months after initial imaging. 

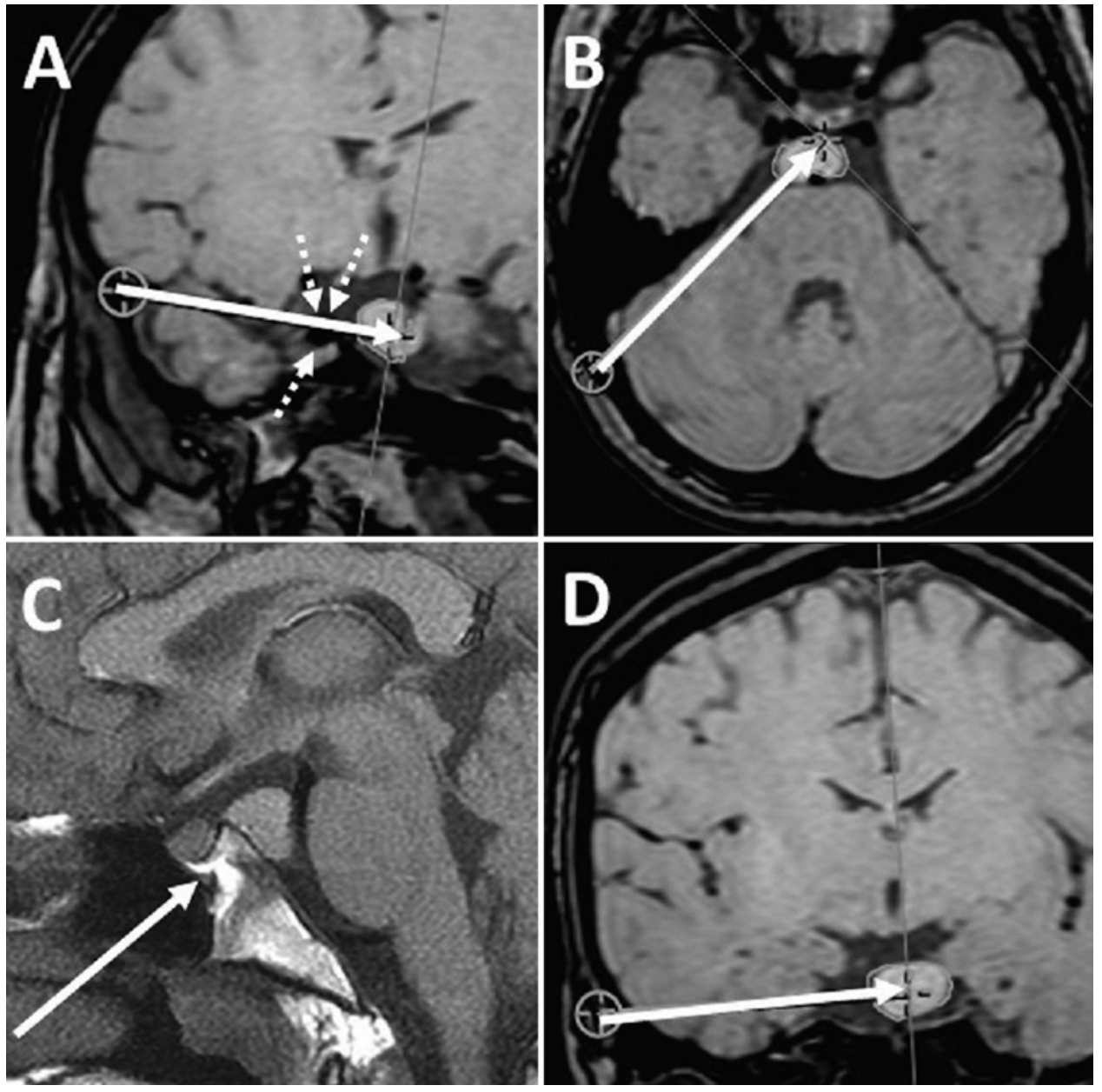

FIG. 6. Trajectory view of the reconstructed MR images. A: Trajectory of the transsylvian approach (white solid arrow). Dotted arrows show the posterior clinoid process. B: Trajectory of the lateral suboccipital approach (white solid arrow). C: Trajectory of the endonasal transclival approach (white solid arrow). D: Trajectory of the subtemporal approach (white solid arrow).

of the prepontine cistern. This approach does not require drilling of any deep-seated bones or retraction of the brainstem. Although retraction of the temporal lobe is necessary with the subtemporal approach, this approach allows observation of the entire cyst. In addition, it is important to prevent contusion of the temporal lobe by shortening retraction time, gently retracting the temporal lobe, and achieving sufficient drainage of cerebrospinal fluid from the lateral ventricle.

\section{Conclusions}

We have reported a pediatric case of enlarging ectopic Rathke's cleft cyst in the prepontine cistern. To our knowledge, no pediatric case of Rathke's cleft cyst enlarging only in the prepontine cistern has been reported previously. Total resection of the cisternal portion of the cyst was successfully achieved using a subtemporal approach. Since cyst remnants may be present, we have recommended annual follow-up imaging for this patient.

\section{References}

1. Al-Ahmed IH, Boughamoura M, Dirks P, Kulkarni AV, Rut- ka JT, Drake JM: Neurosurgical management of neurenteric cysts in children. J Neurosurg Pediatr 11:511-517, 2013

2. Arora R, Rani JY, Uppin MS, Ca R: An unusual case of large posterior fossa neurenteric cyst involving bilateral cerebellopontine angle cisterns: report of a rare case and review of literature. Pol J Radiol 79:356-359, 2014

3. Ben Hamouda K, Khaldi M, Jemel H, Ben Ismail M, Zemmel I: Rathke cleft cyst of the sphenoid bone and nasopharynx. Case illustration. J Neurosurg 103:1095, 2005

4. Chanda A, Nanda A: Anatomical study of the orbitozygomatic transsellar-transcavernous-transclinoidal approach to the basilar artery bifurcation. J Neurosurg 97:151-160, 2002

5. Chuang CC, Chen YL, Jung SM, Pai PC: A giant retroclival Rathke's cleft cyst. J Clin Neurosci 17:1189-1191, 2010

6. Fan J, Qi S, Peng Y, Zhang XA, Qiu B, Pan J: An isolated primary Rathke's cleft cyst in the cerebellopontine angle. J Neurosurg 121:846-850, 2014

7. Filho FL, Tatagiba M, Carvalho GA, Weichhold W, Klekamp J, Samii M: Neurenteric cyst of the craniocervical junction. Report of three cases. J Neurosurg 94 (1 Suppl):129-132, 2001

8. Fleming H, Murayama S, Dacey RG Jr: Posterior fossa epithelial cyst of ectodermal origin. Neurosurgery 29:459464, 1991

9. Graziani N, Dufour H, Figarella-Branger D, Donnet A, 
Bouillot P, Grisoli F: Do the suprasellar neurenteric cyst, the Rathke cleft cyst and the colloid cyst constitute a same entity? Acta Neurochir (Wien) 133:174-180, 1995

10. Hirai O, Kawamura J, Fukumitsu T: Prepontine epitheliumlined cyst. Case report. J Neurosurg 55:312-317, 1981

11. Jaskólski DJ, Wróbel-Wiśniewska G, Papierz W, Góraj B, Zawirski M: Colloid-like cyst located in the prepontine region. Surg Neurol 60:260-264, 2003

12. Kim E: A case of ectopic Rathke's cleft cyst in the prepontine cistern. J Korean Neurosurg Soc 52:152-155, 2012

13. Naylor MF, Scheithauer BW, Forbes GS, Tomlinson FH, Young WF: Rathke cleft cyst: CT, MR, and pathology of 23 cases. J Comput Assist Tomogr 19:853-859, 1995

14. Prevedello DM, Fernandez-Miranda JC, Gardner P, Madhok R, Sigounas D, Snyderman CH, et al: The transclival endoscopic endonasal approach (EEA) for prepontine neuroenteric cysts: report of two cases. Acta Neurochir (Wien) 152:1223-1229, 2010

15. Valencia Calderón C, Castro Cevallos A, Calderón Valdiviezo A, Escobar Dávila R, Parra Rosales F, Quispe Alcocer J, et al: [Neuronavigation in the surgical planning of callosotomy.] Neurocirugia (Astur) 27:186-193, 2016 (Span)

16. Zhou L, Luo L, Hui X, Chen H, Yu B, Guo G, et al: Primary
Rathke's cleft cyst in the cerebellopontine angle associated with apoplexy. Childs Nerv Syst 26:1813-1817, 2010

\section{Disclosures}

The authors report no conflict of interest concerning the materials or methods used in this study or the findings specified in this paper.

\section{Author Contributions}

Conception and design: Nonaka, Yamanouchi. Acquisition of data: Nonaka, Kamei, Uemura, Yamanouchi. Analysis and interpretation of data: Nonaka, Kamei, Komori, Asai. Drafting the article: Nonaka, Kamei, Asai. Critically revising the article: Nonaka, Uemura, Yamanouchi, Iwata, Takeda, Hashiba, Yoshimura, Asai. Reviewed submitted version of manuscript: all authors. Approved the final version of the manuscript on behalf of all authors: Nonaka. Study supervision: Nonaka, Asai.

\section{Correspondence}

Masahiro Nonaka, Department of Neurosurgery, Kansai Medical University, 2-3-1, Shinmachi, Hirakata City, Osaka 573-1191, Japan.email: nonakamasa65@gmail.com. 